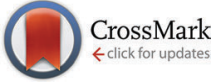

Cite this: New J. Chem., 2016, 40,3571

Received (in Montpellier, France) 14th January 2016 Accepted 17th February 2016 DOI: 10.1039/c6nj00136j

www.rsc.org/njc

\title{
Synthesis, structure, magnetic and magnetocaloric properties of a series of $\left\{\mathrm{Cr}_{4}^{\prime \prime \prime} \mathrm{Ln}^{\prime \prime \prime}\right\}$ complexes $\dagger$
}

\author{
Olivier Blacque, ${ }^{a}$ Asma Amjad, ${ }^{\mathrm{b}}$ Andrea Caneschi, ${ }^{\mathrm{b}}$ Lorenzo Sorace ${ }^{{ }^{\mathrm{b}}}$ and \\ Pierre-Emmanuel Car*a
}

\begin{abstract}
The hydrothermal reaction of $\mathrm{CrCl}_{3} \cdot 6 \mathrm{H}_{2} \mathrm{O}$ and $\mathrm{Ln}\left(\mathrm{NO}_{3}\right)_{3} \cdot \mathrm{xH}_{2} \mathrm{O}$ in the presence of di(2-pyridil)ketone, and sodium acetate in water leads to the formation of a series of $\left[\mathrm{Cr}_{4} \mathrm{Ln}\left(\mathrm{CH}_{3} \mathrm{COO}\right)(\mathrm{pyCOO})\left((\mathrm{py})_{2} \mathrm{COO}\right)_{4}\right] \cdot\left(\mathrm{NO}_{3}\right)_{2} \cdot n \mathrm{H}_{2} \mathrm{O}$ complexes (with $\mathrm{Ln}=\mathrm{Gd}(\mathrm{II}), \mathrm{Tb}(\mathrm{III}), \mathrm{Dy}(\mathrm{III})$, and $n=19$ or 20 ). The four newly synthesized complexes were characterized by single crystal X-ray diffraction technique and their magnetic properties were fully investigated by $\mathrm{dc}$ (direct current) and ac (alternating current) magnetic susceptibility measurements. Single crystal $X$-ray studies revealed that the dysprosium derivative crystallizes as two different structural forms: a triclinic $P \overline{1}$ form and a monoclinic $P 2_{1} / n$ form. The gadolinium and the terbium derivatives were isostructural to the dysprosium monoclinic form. Surprisingly, full static and dynamic magnetic studies revealed that none of the synthesized complexes exhibit single molecule magnet behaviour, while the gadolinium derivative displays a magnetocaloric effect (MCE).
\end{abstract}

\section{Introduction}

Heterometallic $3 \mathrm{~d}-4 \mathrm{f}$ coordination complexes have gained substantial interest over the last decade as potential candidates for the design of multifunctional materials, with emphasis on their peculiar magnetic behaviour, such as single molecule magnet, SMM, behaviour ${ }^{1}$ and molecular refrigerants. ${ }^{2}$ For molecular refrigerant properties, the use of weakly exchange coupled 3d-4f systems, based on isotropic ion such as $\mathrm{Gd}(\mathrm{III})^{3}$ and featuring small molecular weight ligands has been proposed. Magnetic refrigeration is based on the magnetocaloric effect (MCE), an isothermal magnetization process, leading to a decrease of magnetic entropy of the material, followed by an adiabatic demagnetization, resulting in a temperature decrease. ${ }^{4}$ Recent studies demonstrated that molecular clusters show a magnetocaloric effect much larger than that found in the best intermetallic and lanthanide alloys at low temperatures, and magnetic nanoparticles employed commercially, due to the increase of magnetic entropy at low temperature when these materials are subjected to an adiabatic demagnetization. In the last few years, it has been demonstrated that useful chemical

\footnotetext{
${ }^{a}$ Department of Chemistry, University of Zurich, Winterthurerstrasse 190, CH-8057 Zurich, Switzerland. E-mail: pierre-emmanuel.car@chem.uzh.ch

${ }^{b}$ Dipartimento di Chimica Ugo Schiff \& UdR INSTM, Università degli Studi di

Firenze, Via della Lastruccia 3-13, 50019 Sesto Fiorentino, Italy.

E-mail: lorenzo.sorace@unifi.it

$\dagger$ Electronic supplementary information (ESI) available: Selected bond lengths, angles, crystal packing and crystal structure. CCDC 1440572 (1a), 1440573 (1b), 1440574 (2) and 1440575 (3). For ESI and crystallographic data in CIF or other electronic format see DOI: 10.1039/c6nj00136j
}

approach consists in combining the essentially isotropic $\mathrm{Gd}(\mathrm{III})$ ion $^{3}\left(4 \mathrm{f}^{7}\right)$ with transition metal ions, such as $\mathrm{Mn}(\mathrm{III}),{ }^{5} \mathrm{Co}(\mathrm{II}),{ }^{6}$ $\mathrm{Ni}(\mathrm{II}){ }^{7} \mathrm{Zn}$ (II), ${ }^{8} \mathrm{Cu}(\mathrm{II}),{ }^{9}$ as well as the isotropic $\mathrm{Cr}(\mathrm{III})$ ion, ${ }^{2 a}$ or the use of high-spin ions such as Fe(III) and Mn(II). ${ }^{2 b, 10}$ Particularly, Cr(III)-Ln(III) complexes, highlighted by a series of papers by Pedersen and co-workers, ${ }^{2 b, 11,17 b, c}$ have recently demonstrated promising magnetocaloric effect through the use of fluoride bridged-clusters, leading to weak exchange interactions and showing relevant magnetic entropy changes.

For the study of single molecule magnets, the use of exchangecoupled systems, ${ }^{12}$ has been proposed as a viable method to reduce the very efficient quantum tunnelling (QT) processes in zero field often observed in mononuclear if systems. This may hamper the observation of magnetic bistability despite very large anisotropy barriers often reported for $\mathrm{Tb}$ (III) and Dy(III) derivatives. ${ }^{13,14}$ Despite encouraging results ${ }^{15,16}$ there are however two main issues to be solved in the use of $3 \mathrm{~d}-4 \mathrm{f}$ systems for efficient SMMs: (i) the relatively weak exchange coupling provided by lanthanide ions, due to the inner nature of the $4 \mathrm{f}$ orbitals compared to the $3 \mathrm{~d}$ ones; (ii) the relative orientation of the magnetic anisotropy of the $3 \mathrm{~d}$ and $4 \mathrm{f}$ metal ions must be controlled to obtain large global anisotropy.

In our group, we are interested, in particular, in complexes where the core is comprised of lanthanides and chromium: the number of $\mathrm{Cr}(\mathrm{III})-\mathrm{Ln}(\mathrm{III})$ coordination complexes is indeed relatively small, rendering this heterometallic combination a challenging area of chemistry. To the best of our knowledge, the design of new molecular Cr(III)-Ln(III) materials is based on four main chemical approaches. The first one involves the use of $\{\mathrm{Cr}-\mathrm{F}-\mathrm{Ln}\}$ fluoride bridges ${ }^{17}$ while the second one is built 
around cyano-bridged ligands for $\{\mathrm{Cr}-\mathrm{CN}-\mathrm{Ln}\}$ derivatives. ${ }^{18}$ The third and the fourth ones incorporate oxo-bridged and oxalato-bridged ligands respectively for $\{\mathrm{Cr}-\mathrm{O}-\mathrm{Ln}\}^{19,20}$ and $\{\mathrm{Cr}$-OOCCOO-Ln $\}$ derivatives. ${ }^{21}$ While promising results have been obtained for fluoride bridged-ligands as well as on cyano-bridged ligands, only very few example of $\mathrm{Cr}(\mathrm{III})-\mathrm{Ln}$ (III) complexes containing oxo-bridged-ligands and showing SMM behaviour or MCE property have been reported to date. ${ }^{19,22-24}$ It is then clear the need for the synthesis and characterization of further exchange-coupled Cr(III)-Ln(III) systems with oxo bridged-ligands on which to investigate the potentialities of this approach.

We present herein the synthesis, crystal structure studies and investigation of magnetic properties of a series of heterometallic chromium-lanthanide complexes with the general formula $\left[\mathrm{Cr}_{4} \mathrm{Ln}\left(\mathrm{CH}_{3} \mathrm{COO}\right)(\mathrm{pyCOO})_{4}\left((\mathrm{py})_{2} \mathrm{COO}\right)_{4}\right] \cdot\left(\mathrm{NO}_{3}\right)_{2} \cdot n \mathrm{H}_{2} \mathrm{O}$ with $\mathrm{Ln}=$ Gd(III), Tb(III) and Dy(III). The new family was obtained by the short hydrothermal reaction of a lanthanide salt $\mathrm{Ln}\left(\mathrm{NO}_{3}\right)_{3} \cdot x \mathrm{H}_{2} \mathrm{O}$, with the chromium salt $\mathrm{CrCl}_{3} \cdot 6 \mathrm{H}_{2} \mathrm{O}$ in the presence of $\mathrm{CH}_{3} \mathrm{COONa} \cdot 3 \mathrm{H}_{2} \mathrm{O}$ and di(2-pyridil)ketone $\left((\mathrm{py})_{2} \mathrm{CO}\right)$ in water. The new series of complexes has been investigated by single crystal X-ray diffraction techniques, revealing that the Dy(III) derivative crystallizes into two structural forms, triclinic $P \overline{1}$ and monoclinic $P 2_{1} / n$. The magnetic characterization showed that none of the complexes reported in the present manuscript exhibit SMM behaviour, while MCE of reasonable magnitude is observed for the Gd(III) complex.

\section{Experimental section}

\section{Syntheses}

All chemicals were commercially purchased from Sigma-Aldrich, and used without further purification.

$\mathrm{Cr}_{4} \mathrm{Dy}$ (1a) and (1b). $\mathrm{CrCl}_{3} \cdot 6 \mathrm{H}_{2} \mathrm{O}(26.6 \mathrm{mg}, 0.10 \mathrm{mmol})$, $\mathrm{Dy}\left(\mathrm{NO}_{3}\right)_{3} \cdot 6 \mathrm{H}_{2} \mathrm{O}(137 \mathrm{mg}, 0.30 \mathrm{mmol}),(\text { py })_{2} \mathrm{CO}(110.5 \mathrm{mg}$, $0.60 \mathrm{mmol})$ and $\mathrm{CH}_{3} \mathrm{COONa} \cdot 3 \mathrm{H}_{2} \mathrm{O}(81.6 \mathrm{mg}, 0.60 \mathrm{mmol})$ were placed in a $23 \mathrm{~mL}$ Teflon-lined steel autoclave stirred all together in $5 \mathrm{~mL}$ of distilled water. After $10 \mathrm{~min}$, the autoclave was closed and heated at $140{ }^{\circ} \mathrm{C}$ for 2 days, followed by 12 hours of cooling to room temperature. The solution was then filtrated to remove all impurities. The resulting clear solution was kept undisturbed at room temperature. Crystals suitable for X-ray studies were collected after several days. Compounds $\mathbf{1 a}$ and $\mathbf{1 b}$ crystallize simultaneously as a triclinic form and as a monoclinic form. Crystals were manually selected and collected under a stereo microscope exclusively for magnetic measurements and ICP analysis. Quantity of collected crystals for 1a, $m=7.36 \mathrm{mg}$ (yield $1.12 \%$ based on $\left.\mathrm{Dy}\left(\mathrm{NO}_{3}\right)_{3} \cdot 6 \mathrm{H}_{2} \mathrm{O}\right)$. Quantity of collected crystals for $1 \mathbf{b}, m=8.4 \mathrm{mg}$ (yield $1.27 \%$ based on $\mathrm{Dy}\left(\mathrm{NO}_{3}\right)_{3} \cdot 6 \mathrm{H}_{2} \mathrm{O}$ ). Anal. calcd (found \%) for $\mathrm{Cr}_{4} \mathrm{DyN}_{14} \mathrm{O}_{43} \mathrm{C}_{70} \mathrm{H}_{89}$ (1a): C 38.49 (38.60), $\mathrm{N} 8.97$ (8.37), $\mathrm{H} 4.07$ (3.92). Anal. calcd (found \%) for $\mathrm{Cr}_{4} \mathrm{Dy}-$ $\mathrm{N}_{14} \mathrm{O}_{44} \mathrm{C}_{70} \mathrm{H}_{91}$ (1b): C 38.17 (38.55), N 8.90 (8.29), H 4.13 (3.96).

$\mathrm{Cr}_{4} \mathbf{T b}$ (2). The synthetic procedure was identical to compounds $1 \mathrm{a}$ and 1b. Dy $\left(\mathrm{NO}_{3}\right) \cdot 6 \mathrm{H}_{2} \mathrm{O}$ was replaced by $\mathrm{Tb}\left(\mathrm{NO}_{3}\right)_{3}$. $5 \mathrm{H}_{2} \mathrm{O}$ (130.5 mg, $0.3 \mathrm{mmol}$ ). Quantity of collected crystals, $m=6.2 \mathrm{mg}$ (yield $0.94 \%$ based on $\left.\mathrm{Tb}\left(\mathrm{NO}_{3}\right)_{3} \cdot 5 \mathrm{H}_{2} \mathrm{O}\right)$. Anal. calcd (found \%) for $\mathrm{Cr}_{4} \mathrm{TbN}_{14} \mathrm{O}_{44} \mathrm{C}_{70} \mathrm{H}_{91}$ (2): C 38.23 (38.68), $\mathrm{N} 8.91$ (8.40), H 4.14 (3.97).

$\mathrm{Cr}_{4} \mathbf{G d}$ (3). The synthetic procedure was identical to compounds 1a and 1b. Dy $\left(\mathrm{NO}_{3}\right) \cdot 6 \mathrm{H}_{2} \mathrm{O}$ was replaced by $\mathrm{Gd}\left(\mathrm{NO}_{3}\right)_{3}$. $6 \mathrm{H}_{2} \mathrm{O}$ (135.4 mg, $0.3 \mathrm{mmol}$ ). Quantity of collected crystals, $m=3 \mathrm{mg}$ (yield $0.45 \%$ based on $\mathrm{Gd}\left(\mathrm{NO}_{3}\right)_{3} \cdot 6 \mathrm{H}_{2} \mathrm{O}$ ). Anal. calcd (found \%) for $\mathrm{Cr}_{4} \mathrm{GdN}_{14} \mathrm{O}_{44} \mathrm{C}_{70} \mathrm{H}_{91}$ (3): C 38.27 (38.66), N 8.92 (8.40), H 4.14 (3.91).

\section{X-ray crystallography}

Single crystal X-ray diffraction data were collected at 183(1) K on an Oxford Instruments Cryojet XL cooler and on an Agilent Technologies Xcalibur Ruby area detector diffractometer using a single wavelength enhance X-ray source with Mo $\mathrm{K}_{\alpha}$ radiation $(\lambda=0.71073 \AA)^{25}$ from a micro-focus X-ray source for complexes 1a and 1b, and on a Agilent Technologies SuperNova Atlas area detector diffractometer using a single wavelength enhance X-ray source with $\mathrm{Cu} \mathrm{K}_{\alpha}$ radiation $(\lambda=1.54184 \AA)$, from a microfocus X-ray source, for 2 and 3.

The selected suitable single crystals were mounted using polybutene oil on a flexible loop fixed on a goniometer head and immediately transferred to the diffractometer. Pre-experiment, data collection, data reduction and analytical absorption correc$\operatorname{tion}^{26}$ were performed with the program suite CrysAlisPro. ${ }^{27}$ Using Olex $2^{28}$ the structures were solved by the SHELXS97 ${ }^{29}$ $(\mathbf{1 a}, \mathbf{1 b}, 2)$ or $\operatorname{SHELXT}^{30}(\mathbf{3})$ and then refined with the SHELXL ${ }^{31}$ program package by full-matrix least-squares minimization on $F^{2}$. Platon ${ }^{32}$ was used to check the results of the X-ray analyses. For more details about the data collections and refinements parameters, see the crystallographic information files and the ESI. $\dagger$ Crystal data and refinement parameters of 1a, 1b, 2 and 3 are given in Table 1.

\section{Physical measurements}

Manually collected crystals were analysed by AES-ICP method. The direct current (dc) magnetic susceptibility measurements as well as the field dependence of the magnetization ( $M$ vs. $H$ ) were carried out on a Quantum Design MPMS SQUID magnetometer on microcrystalline samples pressed in a pellet to avoid field induced orientation of the crystallites. The ac magnetic susceptibility measurements were carried out on a Quantum Design PPMS in ac mode at both zero and applied external dc field in the presence of 5 Oe oscillating magnetic field. Isothermal magnetization curves for 3 were performed using the VSM option of the Quantum Design PPMS. Raw data were reduced to paramagnetic molar susceptibilities using molecular formula obtained by X-ray data, including all water molecules. This also allowed to evaluate intrinsic diamagnetism of the sample by use of corresponding Pascal's constants.

\section{Results and discussion}

\section{Syntheses and crystal growth}

All compounds were obtained by a fast hydrothermal treatment of a mixture containing all starting materials and followed by 
Table 1 Crystallographic data and structural refinements for compounds $\mathbf{1 a}, \mathbf{1 b}, \mathbf{2}$ and $\mathbf{3}$

\begin{tabular}{|c|c|c|c|c|}
\hline & 1a & $1 b$ & 2 & 3 \\
\hline Formula weight $\left(\mathrm{g} \mathrm{mol}^{-1}\right)$ & 2185.05 & 2203.06 & 2199.48 & 2197.81 \\
\hline Temperature (K) & 183(1) & 183(1) & 183(1) & 183(1) \\
\hline Crystal system & Triclinic & Monoclinic & Monoclinic & Monoclinic \\
\hline Space group & $P \overline{1}$ & $P 2_{1} / n$ & $P 2_{1} / n$ & $P 2_{1} / n$ \\
\hline$a(\AA)$ & $12.3890(3)$ & 16.7984(3) & $16.7168(3)$ & $16.81501(17)$ \\
\hline$\alpha\left(^{\circ}\right)$ & $80.244(2)$ & 90 & 90 & 90 \\
\hline$\beta\left(^{\circ}\right)$ & $82.550(2)$ & $95.739(2)$ & $95.6450(17)$ & $95.8109(9)$ \\
\hline$\gamma\left({ }^{\circ}\right)$ & $85.849(2)$ & 90 & 90 & 90 \\
\hline$V\left(\AA^{3}\right)$ & $4408.06(19)$ & 8914.1(3) & $8907.3(3)$ & $8947.10(14)$ \\
\hline$Z$ & 2 & 4 & 4 & 4 \\
\hline$\rho_{\text {calc }}\left(\mathrm{g} \mathrm{cm}^{-3}\right)$ & 1.646 & 1.642 & 1.640 & 1.632 \\
\hline Crystal size & $0.24 \times 0.1 \times 0.06$ & $0.27 \times 0.07 \times 0.02$ & $0.14 \times 0.05 \times 0.03$ & $0.32 \times 0.14 \times 0.04$ \\
\hline$F(000)$ & 2226 & 4492 & 4488 & 4484 \\
\hline Data/restraints/parameters & $19940 / 0 / 1139$ & $20415 / 57 / 1159$ & $12153 / 60 / 1096$ & $18265 / 69 / 1205$ \\
\hline Goodness-of-fit & 1.052 & 1.052 & 1.050 & 1.037 \\
\hline$R_{1}^{a}[I>2 \sigma(I)]$ & 0.0474 & 0.0504 & 0.0705 & 0.0470 \\
\hline $\mathrm{w} R_{2}^{b}$ & 0.0977 & 0.1237 & 0.2068 & 0.1247 \\
\hline$R_{1}^{a}[I>2 \sigma(I)]$ (all data) & 0.0777 & 0.0763 & 0.0949 & 0.0594 \\
\hline $\mathrm{w} R_{2}^{b}$ (all data) & 0.1145 & 0.1374 & 0.2262 & 0.1347 \\
\hline
\end{tabular}

the slow evaporation of the filtrates. Interestingly, the hydrothermal treatment at $140{ }^{\circ} \mathrm{C}$ during 2 days and 12 hours of cooling to room temperature lead to the formation of the gem-diol dianion form, (py) ${ }_{2} \mathrm{COO}_{2}{ }^{-}$, by reduction of the di(2-pyridil)ketone ligand ${ }^{33}$ and to the decomposition of this ligand in a simplified ion form (py) $\mathrm{COO}^{-}$. Suitable crystals for single crystal X-ray diffraction analysis were collected after few weeks, by slow evaporation of the solutions obtained from the filtration of the reaction mixture after 2 day of heating and 12 hours of cooling to room temperature. The dysprosium derivative crystallizes simultaneously as two structural forms that are the triclinic and the monoclinic forms respectively for $\mathbf{1 a}$ and $\mathbf{1 b}$. The two forms were easily separated manually under a stereomicroscope, due to their different shape forms. As for compounds $\mathbf{1 a}$ and $\mathbf{1 b}$, compounds $\mathbf{2}$ and $\mathbf{3}$ were also collected manually, due to the low quantity of crystals present in solution, and in order to get samples in a pure form.

\section{Crystal structures}

Full crystallographic data and structural refinements for $\mathbf{1 a}, \mathbf{1 b}$, $\mathbf{2}$ and $\mathbf{3}$ are shown in Table 1 . Compound $\mathbf{1 a}$ crystallizes in the triclinic $P \overline{1}$ space group, while compounds $\mathbf{1 b}, \mathbf{2}$ and $\mathbf{3}$ are isostructural and crystallize in the monoclinic $P 2_{1} / n$ space group. The single crystal X-ray diffraction investigations revealed that the four newly synthesized compounds possess an identical $\left\{\mathrm{Cr}_{4} \mathrm{Ln}\left(\mathrm{CH}_{3} \mathrm{COO}\right)(\mathrm{pyCOO})_{4}\left((\mathrm{py})_{2} \mathrm{COO}\right)_{4}\right\}$ structural motif surrounded by nitrate anions and water molecules. As a result only compound $\mathbf{1 a}$ is fully described here. Selected interatomic bond distances (e.g. Cr $\cdots \mathrm{O}, \mathrm{Ln} \cdots \mathrm{O}, \ldots)$ ) and angles for compounds 1a, 1b, 2 and $\mathbf{3}$ are reported in Table S4 (ESI $\dagger$ ).
Compounds $\mathbf{1 a}$ and $\mathbf{1 b}$ crystallize simultaneously as two structural forms, respectively in the triclinic $P \overline{1}$ and monoclinic $P 2_{1} / n$ space groups and differ only by their water molecule content.

As shown in Fig. 1, the $\left\{\mathrm{Cr}_{4} \mathrm{Dy}\left(\mathrm{CH}_{3} \mathrm{COO}\right)(\mathrm{pyCOO})_{4}\left((\mathrm{py})_{2} \mathrm{COO}\right)_{4}\right\}$ complex consists of one central Dy(III) ion surrounded by four $\mathrm{Cr}$ (III) ions forming, from a top view (see Fig. 1, top), a diamondshape structure in which two $\mathrm{Cr}$ (III) ions lies above the average plane identified by the $\mathrm{Cr}(\mathrm{III})-\mathrm{O}-\mathrm{Ln}$ (III)-O-Cr(III) average plane (see Fig. 1, bottom).

The Dy(III) ion is in a 8 -fold coordination geometry of very low symmetry (see Fig. 2, left). Indeed, analysis of the coordination polyhedron via SHAPE software ${ }^{34}$ did not provide any reasonable agreement with regular 8-vertex polyhedral (see ESI, $\dagger$ Table S1). The distortion with respect to the square-antiprismatic geometry is highlighted in Fig. 2. The eight oxygen atoms belong to one chelating acetate ligand on the top and four gem-diol ligands to which two are chelating the lanthanide (see Fig. 2, right). Dy. .O bond lengths range from 2.365(2) to 2.431(2) $\AA$, for the oxygen atoms of the gem-diol ligands, and 2.348(2) A and 2.396(2) ̊ for the oxygen atoms of the acetate ligand.

Each $\mathrm{Cr}(\mathrm{III})$ ions is octahedrally coordinated and holding an identical coordination geometry with three oxygen atoms and three nitrogen atoms (see Fig. 3), belonging to two gem-diol ligands and one (py) $\mathrm{COO}^{-}$. The $\mathrm{Cr} \cdots \mathrm{O}$ bond distances range from $1.923(2)$ to $1.982(2) \AA$, while the $\mathrm{Cr} \cdots \mathrm{N}$ bond lengths range from 2.041(3) to 2.079(3) Å.

The diamond-shape type structure is formed by the heterometallic core composed by the Dy(III) and the four Cr(III) ions. The structural study shows (see Fig. 4) that two opposite 

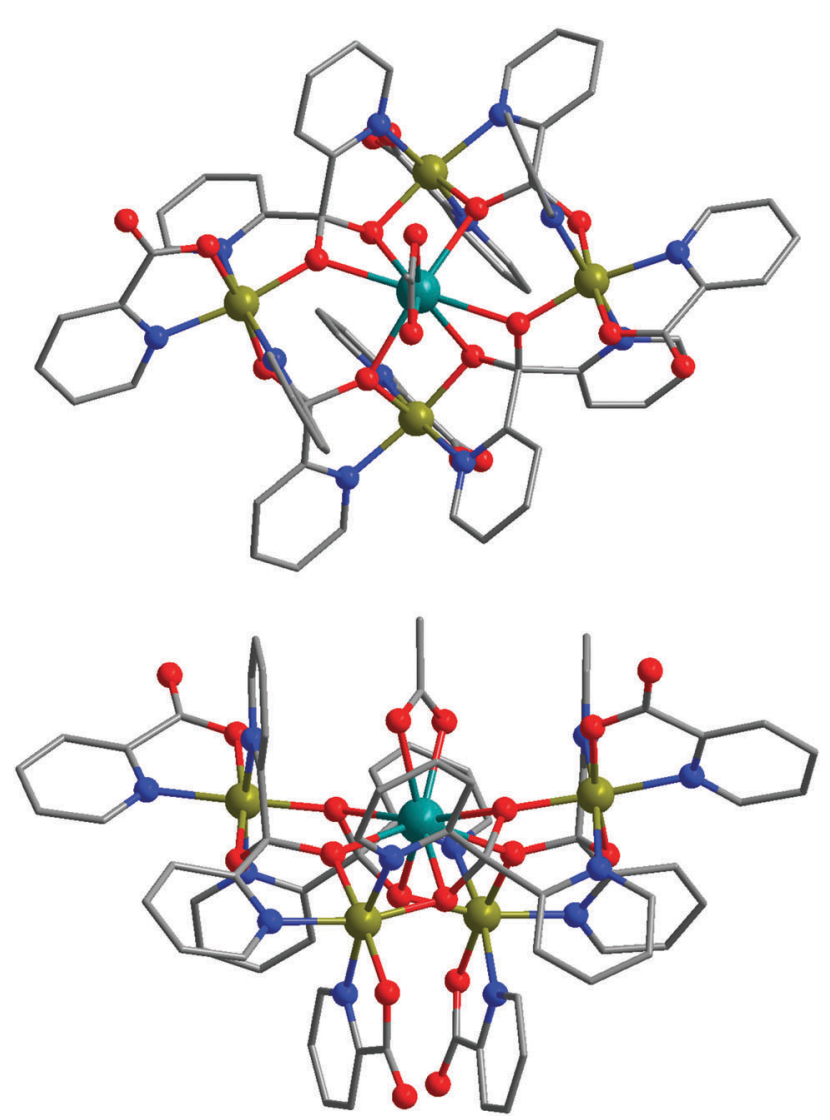

Fig. 1 Molecular structure of 1a. Colour code: Dy: teal, Cr: yellow-green, $\mathrm{O}$ : red, N: blue, C: grey. Hydrogen atoms and solvent molecules have been omitted for clarity.
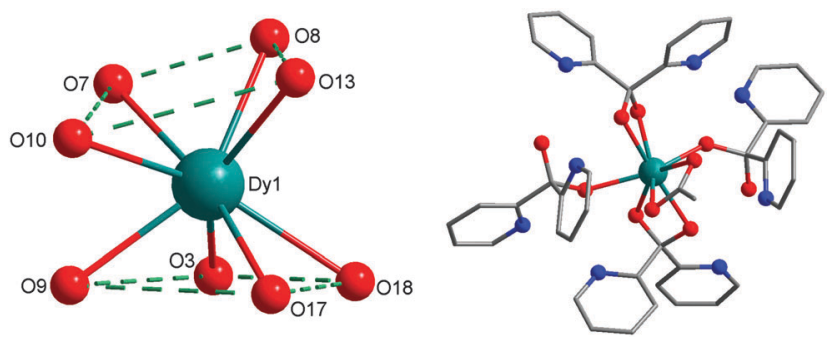

Fig. 2 Left: Local geometry of the Dy ion. Right: Top view of the local environment of the Dy ion. Colour code: Dy: teal, O: red, N: blue, C: grey. Hydrogen atoms have been omitted for clarity.

chromium ions ( $\mathrm{Cr} 2$ and $\mathrm{Cr} 4)$ are almost aligned with the dysprosium ion, while the two others $\mathrm{Cr}$ ions (Cr1 and $\mathrm{Cr} 3$ ) are placed below the alignment of the previous three atoms. The interatomic Dy. . Cr distances range are represented by two short distances of 3.4399(6) and 3.4436(6) $\AA$, for the $\mathrm{Cr}$ ions located below the Dy ion, and two long distances of 3.9489(6) and 3.9809(7) A for the Cr ions located in the relatively same line than the Dy ion. The interatomic $\mathrm{Cr}$. . Cr distances are of 5.2198(7) A for the shortest, and of 7.8419(8) for the longest. The pseudo-alignment made by $\mathrm{Cr} 2 \mathrm{Dy} 1 \mathrm{Cr} 4$ possesses an angle of $162.923(14)^{\circ}$, close to the value of $180^{\circ}$ for a perfect alignment. The Cr1Dy1Cr3 angle made by the dysprosium ion and the two

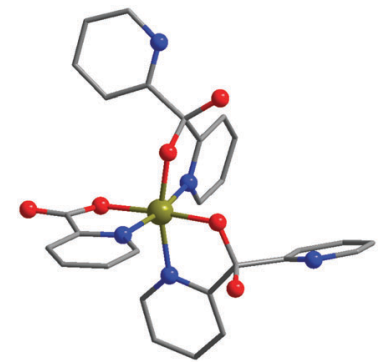

Fig. 3 Local environment around the chromium ions. Colour code: $\mathrm{Cr}$ : yellow-green, O: red, N: blue, C: grey. Hydrogen atoms have been omitted for clarity.

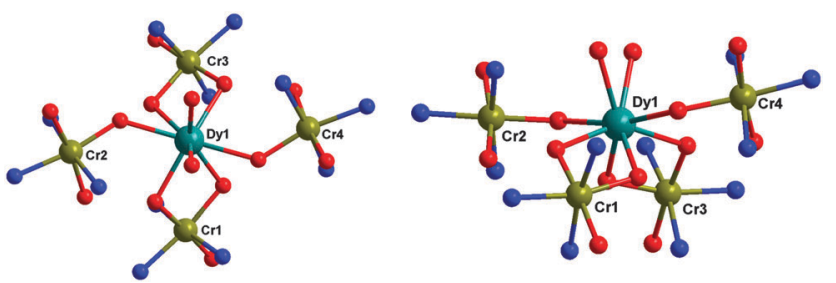

Fig. 4 Top view (left) and side view (right) of the $\left\{\mathrm{Cr}_{4} \mathrm{Dy}\right\}$ metal core center in complex 1a. Colour code: Dy: teal, Cr: yellow-green, O: red, N: blue, C: grey. Hydrogen atoms, carbon atoms and solvent molecules have been omitted for clarity.

chromium ions below the pseudo-alignment is of $110.041(16)^{\circ}$. In the monoclinic Dy complex $\mathbf{1 b}$, the bond lengths range from

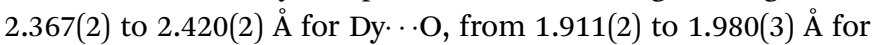

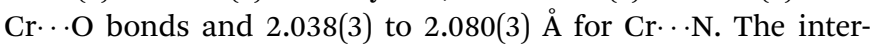
atomic Dy . . Cr distances are of 3.4478(7) and 3.4534(7) $\AA$ for the shortest, and of 3.9631(8) and 3.9837(8) A for the longest, in line with the distances observed in complex 1a. All complexes possess an identical arrangement of their $\left\{\mathrm{Cr}_{4} \operatorname{Ln}\right\}$ metal core center. Nonetheless, complex $\mathbf{1 a}$ crystallizing in the $P \overline{\mathbf{1}}$ triclinic space group, shows a slightly more extended pentanuclear core, compared to complexes $\mathbf{1 b}, \mathbf{2}$ and 3. Indeed, the Cr1Dy1Cr3 angle of $110.04^{\circ}$ in $1 \mathrm{a}$ is slightly bigger than the same angles in 1b, 2 and 3, with values of $107.20^{\circ}, 106.99^{\circ}$ (for Cr1Tb1Cr3) and $106.97^{\circ}$ respectively (for $\mathrm{Cr} 2 \mathrm{Gd} 1 \mathrm{Cr} 3$, see Fig. 6).

\section{Magnetic characterization}

Results of dc magnetic characterization are reported in Fig. 5 in the form of $\chi T$ vs. $T$ plot for 1a, 2 and 3, (complex 1b providing superimposable curves to those of 1a). At room temperature, the observed $\chi T$ values of 21.6 and $19.21 \mathrm{~cm}^{3} \mathrm{~K} \mathrm{~mol}^{-1}$ for Dy(III) and $\mathrm{Tb}$ (III) derivatives, respectively, are in good agreement with 21.65 and $19.3 \mathrm{~cm}^{3} \mathrm{~K} \mathrm{~mol}^{-1}$, expected for uncorrelated spins of the aforementioned lanthanide ions (Dy(III): $J=15 / 2, g_{J}=4 / 3$; $\left.\mathrm{Tb}(\mathrm{III}): J=6, g_{J}=3 / 2\right)$ and four $\mathrm{Cr}(\mathrm{III})\left(S_{\mathrm{Cr}}=3 / 2, g=1.98\right)$ ions. As expected for lanthanide containing complexes, the $\chi T$ product slowly decreases on lowering temperature from $300 \mathrm{~K}$ to $50 \mathrm{~K}$ to thermal depopulation of the excited states of the ground multiplets of the lanthanide(III) ions, split by ligand field effects. The more rapid decrease observed below $50 \mathrm{~K}$ may be attributed to the effect of both intramolecular exchange coupling, either 

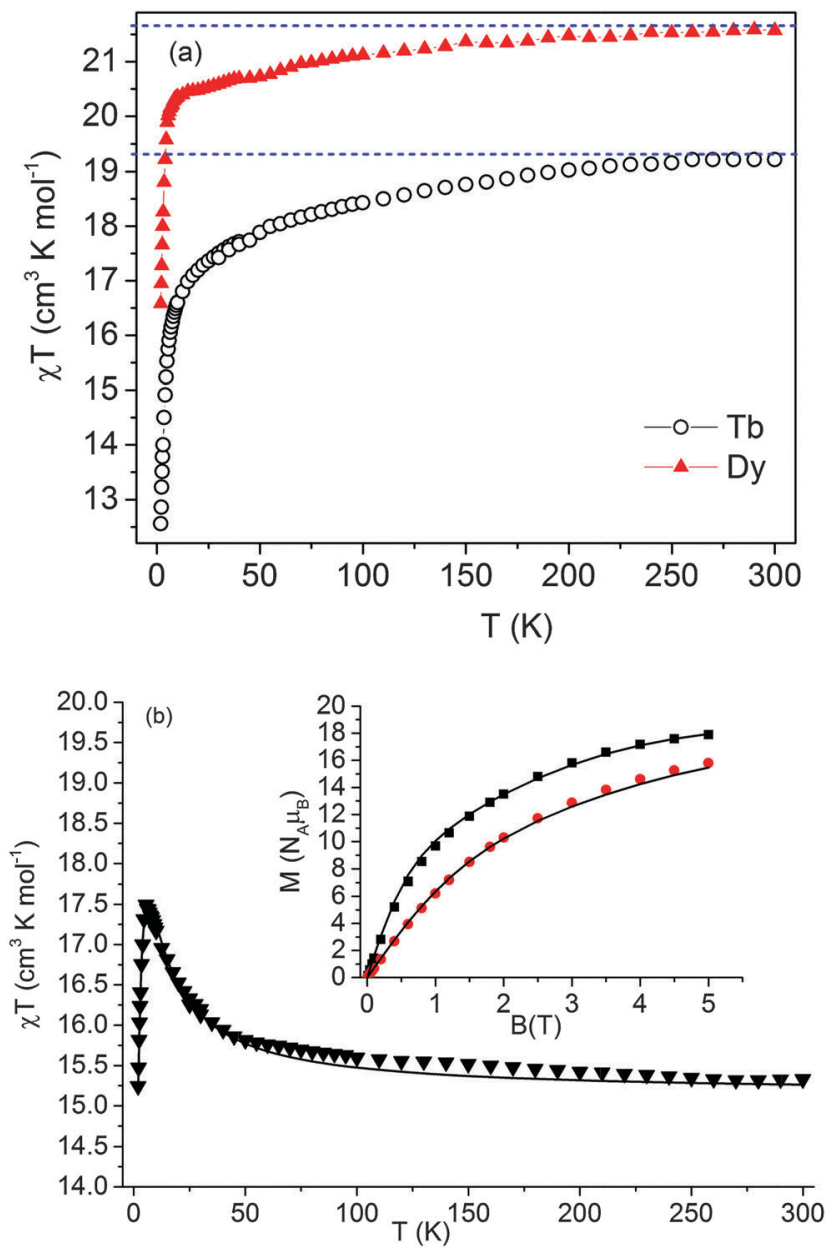

Fig. 5 (a) $\chi T$ vs. $T$ plots for $1 \mathrm{a}$ and 2 , (b) $\chi T$ vs. $T$ for 3 and best fit (continuous line) of the experimental data using model and parameters reported in the text. In the inset, the isothermal magnetization curve at $1.9 \mathrm{~K}$ (squares) and $4.5 \mathrm{~K}$ (red circles) along with best fit curves (continuous lines) are reported. In both plots, the solid lines indicate the expected single-ion $\chi T$ value for $\mathrm{Ln}-\mathrm{Cr}$ complex.

Ln-Cr or Cr-Cr one, and crystal field effects leading to a minimum value of 16.57 and $12.7 \mathrm{~cm}^{3} \mathrm{~K} \mathrm{~mol}^{-1}$ for Dy(III) and $\mathrm{Tb}$ (III) at $1.9 \mathrm{~K}$, respectively. Due to the largely anisotropic nature of both Dy(III) and Tb(III) magnetic moments, a modelling of the data using the standard HDvV Hamiltonian was not possible. However, the isothermal $M v s$. $H$ curves are clearly far from saturation even at $5 \mathrm{~T}$, indicating either large anisotropy or the presence of low-lying excited states close to ground one. Since ac susceptibility measurements as a function of frequency at zero and applied external magnetic field ( 2 KOe) and variable temperature did not show any out-of-phase signal for either $\mathbf{1}$ or $\mathbf{2}$, indicating very fast relaxation process and a lack of SMM behaviour, the latter explanation appears more reasonable.

A more detailed analysis of the magnetic behaviour was on the contrary, possible for 3 , which contains the orbitally non degenerated $\operatorname{Gd}($ III) ion with $S=7 / 2$. For this complex, the magnetic data shows a room temperature value consistent with independent spins (expected spin-only value for $g=2.00$ : $15.38 \mathrm{~cm}^{3} \mathrm{~K} \mathrm{~mol}^{-1}$; measured: $15.3 \mathrm{~cm}^{3} \mathrm{~K} \mathrm{~mol}^{-1}$ ). The $\chi T$ product starts to increase on lowering temperature witnessing intramolecular ferromagnetic exchange coupling interactions. However, the maximum value of $17.5 \mathrm{~cm}^{3} \mathrm{~K} \mathrm{~mol}^{-1}$ reached at $5 \mathrm{~K}$, is much lower than the one of $49.88 \mathrm{~cm}^{3} \mathrm{~K} \mathrm{~mol}^{-1}$ expected for a full ferromagnetic state $(S=19 / 2)$, indicating that antiferromagnetic interactions are also active. Accordingly the value decrease to $15.2 \mathrm{~cm}^{3} \mathrm{~K} \mathrm{~mol}^{-1}$ on further lowering temperature to $1.9 \mathrm{~K}$. This qualitative picture is confirmed by the isothermal field dependent curves (see Fig. 5, inset), which are still far from saturation at $5 \mathrm{~T}$, showing magnetization value which are below the maximum expected value of $19 \mu_{\mathrm{B}}$.

Following these considerations and based on the molecular structure derived by X-rays, we attempted a fit of $\chi T$ data using the following isotropic Hamiltonian: ${ }^{35}$

$$
\hat{H}=-2 J_{\mathrm{Gd}-\mathrm{Cr}} \sum \mathbf{S}_{\mathrm{Gd}} \cdot \mathbf{S}_{\mathrm{Cr}}-2 J_{\mathrm{Cr}-\mathrm{Cr}} \sum \mathbf{S}_{\mathrm{Cr}} \cdot \mathbf{S}_{\mathrm{Cr}}
$$

where $\mathbf{S}$ are the spin operator, $J$ s are the isotropic exchange coupling constants. To avoid over parametrization, we considered a single, averaged $J_{\mathrm{Gd}-\mathrm{Cr}}$ interaction value, despite the quite different geometrical parameters characterizing the exchange coupling paths of $\mathrm{Gd}(\mathrm{III})$ ion with $\mathrm{Cr} 1$ and $\mathrm{Cr} 4$, compared to that with Cr2 and Cr3. Best fit of the $\chi T$ vs. $T$ data was obtained ${ }^{36}$ fixing $g_{\mathrm{Cr}}=1.98$ and $g_{\mathrm{Gd}}=1.99$ and provided $J_{\mathrm{Gd}-\mathrm{Cr}}=0.25 \pm$ $0.05 \mathrm{~cm}^{-1}$ and $J_{\mathrm{Cr}-\mathrm{Cr}}=-0.55 \pm 0.05 \mathrm{~cm}^{-1}$. Confirmation of the occurrence of ferromagnetic $\mathrm{Gd}-\mathrm{Cr}$ interaction and of antiferromagnetic $\mathrm{Cr}-\mathrm{Cr}$ ones was obtained by the best fit of the isothermal magnetization curves, which yielded a closely related set of parameters $\left(J_{\mathrm{Gd}-\mathrm{Cr}}=0.17 \pm 0.04 \mathrm{~cm}^{-1}\right.$ and $J_{\text {Cr-Cr }}=-0.35 \pm 0.05 \mathrm{~cm}^{-1}$ ), the small discrepancy being attributable to the neglecting of zero field splitting contributions and to the simplified model of exchange pattern we adopted. We note that no magnetostructural correlation for the Gd(III)-Cr(III) exchange coupling with similar complexes is now possible, since to the best of our knowledge this is the first example of carboxylate-bridged $\mathrm{Gd}-\mathrm{Cr}$ for which exchange coupling values, even if averaged, are reported. ${ }^{17 a}$ Nonetheless, if we refer to fluoride bridged $\mathrm{Gd}(\mathrm{III})-\mathrm{Cr}$ (III) complexes, for which a large deal of work has been performed in past years, ${ }^{2,11,37}$ antiferromagnetic coupling is expected for large bridging angles $\left(>140^{\circ}\right)$ whereas at smaller angles ferromagnetic coupling should occur. ${ }^{17 c}$ This is in reasonable qualitative agreement with the results here reported, considering that all the $\mathrm{Gd}-\mathrm{O}-\mathrm{Cr}$ angles in

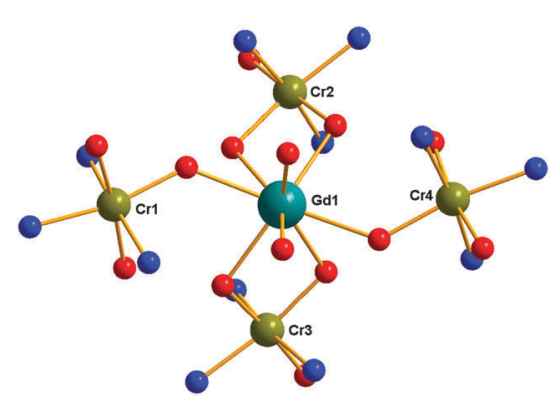

Fig. 6 Top view of the $\left\{\mathrm{Cr}_{4} \mathrm{Gd}\right\}$ metal core center in complex 3 . Colour code: Dy: teal, Cr: yellow-green, O: red, N: blue, C: grey. Hydrogen atoms, carbon atoms and solvent molecules have been omitted for clarity. 
our structure are smaller than $132^{\circ}$, with considerably smaller angles bridges to $\mathrm{Cr} 2$ and $\mathrm{Cr} 3\left(103.86(11)^{\circ}-106.87(12)^{\circ}\right)$, see Fig. 6 (and ESI, $\dagger$ Table S4).

The ground state resulting from best fit parameters is a $S=9 / 2$. However, the small value of the coupling and the presence of competing ferromagnetic and antiferromagnetic interactions, yield a large number of very low lying excited states, all the 2048 levels lying within an energy range of $40 \mathrm{~cm}^{-1}$. This suggests us that this system might be appealing for the investigation of potential MCE effect, which is favoured by this condition.

\section{Investigation of magnetocaloric effect}

In order to explore the possibility that the changes in the magnetocaloric effect in complex $\mathbf{3}$ derivative is large enough to be considered for application purposes, the isothermal magnetic entropy changes $\Delta S_{\mathrm{m}}$ were derived for several applied magnetic field changes $\Delta H=H_{\mathrm{f}}-H_{\mathrm{i}}$. From the isothermal magnetization data at different temperatures the $\Delta S_{\mathrm{m}}$ values were obtained using the Maxwell equation:

$$
-\Delta S_{\mathrm{m}}(T)_{\Delta H}=\int_{H_{\mathrm{i}}}^{H_{\mathrm{f}}}\left(\frac{\mathrm{d} M}{\mathrm{~d} T}\right)_{H} \mathrm{~d} H
$$

and are shown in Fig. 7. As expected an increase in $\Delta H$ corresponds to an increase in $-\Delta S_{\mathrm{m}}$ reaching a maximum value of $18.31 \mathrm{~J} \mathrm{~K}^{-1} \mathrm{~kg}^{-1}$ at $3.5 \mathrm{~K}$, at the highest experimentally achievable $\Delta H=8 \mathrm{~T}$.

This value lies comfortably within the range reported in the literature for gadolinium based systems, ${ }^{38}$ confirming the potentialities of this approach for magnetorefrigeration.

It is worth noting that the maximum observed entropy change is about two thirds of the full available magnetic entropy due to four $\mathrm{Cr}(\mathrm{III})$ and one $\mathrm{Gd}(\mathrm{III}): R \ln \left(2 S_{\mathrm{Gd}}+1\right)+R \ln \left(2 S_{\mathrm{Cr}}+1\right)=$ $28.41 \mathrm{~J} \mathrm{~K}^{-1} \mathrm{~kg}^{-1}$, while it is much higher than that pertaining to the ground state only $\left(S=9 / 2, \Delta S_{\text {m calc }}=8.71 \mathrm{~J} \mathrm{~K}^{-1} \mathrm{~kg}^{-1}\right)$, as well as of the one calculated assuming a pure ferromagnetic state $\left(S=19 / 2, \Delta S_{\text {mcalc }}=11.16 \mathrm{~J} \mathrm{~K}^{-1} \mathrm{~kg}^{-1}\right)$. In this respect, the

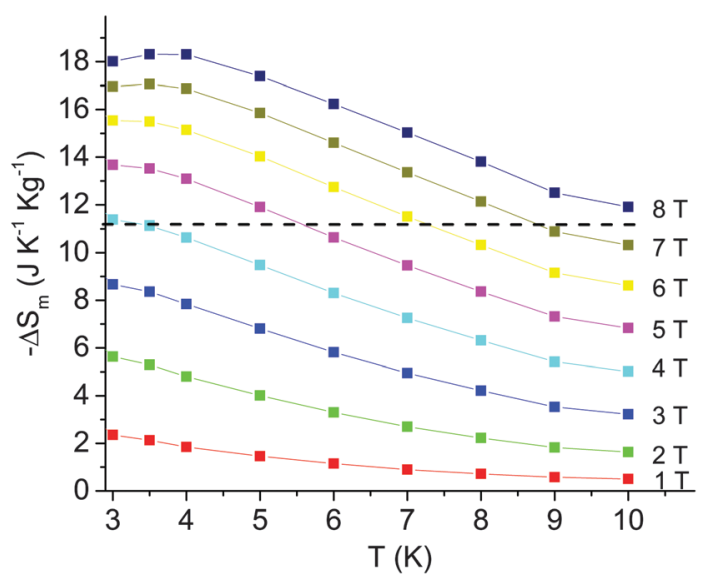

Fig. 7 Experimental magnetic entropy change $-\Delta S_{m}$ as a function of temperature and change in field $\Delta H$, as obtained from the magnetization $M$ vs. $H$ data of complex 3 . Lines are guides to the eyes. existence of competing ferro- and antiferromagnetic interactions of comparable energy scales, resulting in a non-isolated ground spin state, is confirmed to be an essential ingredient for observing MCE of reasonable magnitudes.

\section{Conclusion}

In conclusion, three novel pentanuclear $\mathrm{Ln}-\mathrm{Cr}(\mathrm{III})$ derivatives (Ln = Dy(III), Tb(III) and Gd(III)) have been synthesized, and were structurally and magnetically characterized. Crystal structure studies revealed that the dysprosium derivative crystallizes simultaneously as two structural forms, respectively in the triclinic $P \overline{1}$ and monoclinic $P 2_{1} / n$ space groups. Terbium and gadolinium derivatives are isostructural to the monoclinic dysprosium complex. The magnetic characterization of the three novel Cr(III)-Ln complexes (1a, 2 and 3) revealed that while no ac susceptibility signal could be observed for the three derivatives, the gadolinium one showed interesting magnetocaloric properties. In this complex, the weak coupling between the ions in the complex have lead to the population of multiple paramagnetic states at low temperature, thus leading to a magnetocaloric effect magnitude somewhat in-between the two maxima of the calculated entropy. New experiments on the hydrothermal synthesis approach are currently carried out to improve the yield of all reactions, in order to plan further investigations on the luminescent properties of the $\mathrm{Cr}(\mathrm{III})-$ Ln(III) combination. Moreover, additional experimental procedures are also currently performed to replace the $\mathrm{Cr}$ (III) ion by others transition metals, in order to study the influence of the metal ions on the magnetic behaviour.

\section{Conflict of interest}

The authors declare no competing financial interest.

\section{Acknowledgements}

P.-E. Car acknowledges the financial supports by the University of Zurich (Forschungskredit FK-14-098) and "the Alfred Werner Legat grant”. A. A., A. C. and L. S. acknowledge the financial support of MUIR through "FIRB-Futuro in Ricerca" (RBFR12RPD1).

\section{Notes and references}

1 See for examples: (a) S. Osa, T. Kido, N. Matsumoto, N. Re, A. Pochaba and J. Mrozinski, J. Am. Chem. Soc., 2004, 126, 420; (b) R. Sessoli, D. Gatteschi and J. Villain, Molecular Nanomagnets, Oxford University Press, 2006; (c) J. W. Sharples and D. Collison, Coord. Chem. Rev., 2014, 260, 1; (d) H. L. C. Feltham and S. Brooker, Coord. Chem. Rev., 2014, 276, 1.

2 See for examples: (a) T. Birk, K. S. Pedersen, C. A. Thuesen, T. Weyhermüller, M. Schau-Magnussen, S. Piligkos, H. Weihe, S. Mossin, M. Evangelisti and J. Bendix, Inorg. Chem., 2012, 51, 5435; (b) K. S. Pedersen, G. Lorusso, J. J. Morales, T. Weyhermüller, S. Piligkos, S. K. Singh, D. Larsen, 
M. Schau-Magnussen, G. Rajaraman, M. Evangelisti and J. Bendix, Angew. Chem., Int. Ed., 2014, 53, 2394.

3 M. Evangelisti and E. K. Brechin, Dalton Trans., 2010, 39, 4672.

4 J. Romero Gomez, R. Ferreiro Garcia, A. De Miguel Catoira and M. Romero Gomez, Renewable Sustainable Energy Rev., 2013, 17, 74 .

5 G. Karotsis, S. Kennedy, S. J. Teat, C. M. Beavers, D. A. Fowler, J. J. Morales, M. Evangelisti, S. J. Dalgarno and E. K. Brechin, J. Am. Chem. Soc., 2010, 132, 12983.

6 Y.-Z. Zheng, M. Evangelisti and R. E. P. Winpenny, Chem. Sci., 2011, 2, 99.

7 C. Meseguer, S. Titos-Padilla, M. H. Hänninen, R. Navarrete, A. J. Mota, M. Evangelisti, J. Ruiz and E. Colacio, Inorg. Chem., 2014, 53, 12092.

8 J. Ruiz, G. Lorusso, M. Evangelisti, E. K. Brechin, S. J. A. Pope and E. Colacio, Inorg. Chem., 2014, 53, 3586.

9 See for examples: (a) D. Dermitzaki, G. Lorusso, C. P. Raptopoulou, V. Psycharis, A. Escuer, M. Evangelisti, S. P. Perlepes and T. C. Stamatatos, Inorg. Chem., 2013, 52, 10235; (b) S. K. Langley, B. Moubaraki, C. Tomasi, M. Evangelisti, E. K. Brechin and K. S. Murray, Inorg. Chem., 2014, 53, 13154; (c) T. Rajeshkumar, H. V. Annadata, M. Evangelisti, S. K. Langley, N. F. Chilton, K. S. Murray and G. Rajaraman, Inorg. Chem., 2015, 54, 1661; (d) P. Richardson, D. I. Alexandropoulos, L. Cunha-Silva, G. Lorusso, M. Evangelisti, J. Tang and T. C. Stamatatos, Inorg. Chem. Front., 2015, 2, 945.

10 E. Colacio, J. Ruiz, G. Lorusso, E. K. Brechin and M. Evangelisti, Chem. Commun., 2013, 49, 3845.

11 C. A. Thuesen, K. S. Pedersen, M. Schau-Magnussen, M. Evangelisti, J. Vibenholt, S. Piligkos, H. Weihe and J. Bendix, Dalton Trans., 2012, 41, 11284.

12 J. D. Rinehart, M. Fang, W. J. Evans and J. R. Long, Nat. Chem., 2011, 3, 538.

13 N. Ishikawa, M. Sugita, T. Ishikawa, S.-Y. Koshihara and Y. Kaizu, J. Am. Chem. Soc., 2003, 125, 8694.

14 M. Gregson, N. F. Chilton, A.-M. Ariciu, F. Tuna, I. F. Crowe, W. Lewis, A. J. Blake, D. Collison, E. J. L. McInnes, E. E. P. Winpenny and S. T. Liddle, Chem. Sci., 2016, 7, 155. 15 L. R. Piquer and E. C. Sanudo, Dalton Trans., 2015, 44, 8771. 16 H. L. C. Feltham, R. Clérac, L. Ungur, L. F. Chibotaru, A. K. Powell and S. Brooker, Inorg. Chem., 2013, 52, 3236.

17 See for examples: (a) A. McRobbie, A. R. Sarwar, S. Yeninas, H. Nowell, M. L. Baker, D. Allan, M. Luban, C. A. Muryn, R. G. Pritchard, R. Prozorov, G. A. Timco, F. Tuna, G. F. S. Whitehead and R. E. P. Winpenny, Chem. Commun., 2011, 47, 6251; (b) J. Dreiser, C. Piamonteze, F. Nolting, K. S. Pedersen, J. Bendix, S. Rusponi and H. Brune, J. Korean Phys. Soc., 2013, 62, 1368; (c) S. K. Singh, K. S. Pedersen, M. Sigrist, C. A. Thuesen, M. Schau-Magnussen, H. Mutka, S. Piligkos, H. Weihe, G. Rajaraman and J. Bendix, Chem. Commun., 2013, 49, 5583; (d) S. K. Langley, B. Moubaraki and K. S. Murray, Dalton Trans., 2015, 44, 912.

18 (a) H.-Z. Kou, S. Gao, C.-H. Li, D. Z. Liao, B. C. Zhou, R.-J. Wang and Y. Li, Inorg. Chem., 2002, 41, 4756; (b) H.-Z. Kou,
B. C. Zhou, S. Gao and R.-J. Wang, Angew. Chem., Int. Ed., 2003, 42, 3288.

19 (a) J. Rinck, G. Novitchi, W. Van den Heuvel, L. Ungur, Y. Lan, W. Wernsdorfer, C. E. Anson, L. F. Chibotaru and A. K. Powell, Angew. Chem., Int. Ed., 2010, 49, 7583; (b) S. K. Langlew, D. P. Wielechowski, V. Vieru, N. F. Chilton, B. Moubaraki, B. F. Abrahams, L. F. Chibotaru and K. S. Murray, Angew. Chem., Int. Ed., 2013, 52, 12014.

20 (a) H. Xiang, W.-G. Lu, W.-X. Zhang and L. Jiang, Dalton Trans., 2013, 42, 867; (b) H. Zhang, Z.-Y. Li, J. Zhu, Y.-X. Yu, J. Ni, B.-J. Ding, D.-Z. Liu and J.-J. Zhang, Inorg. Chem. Commun., 2013, 37, 202.

21 L. Aboshyan-Sorgho, H. Nozary, A. Aebischer, J.-C. G. Bünzli, P.-Y. Morgantini, K. R. Kittilstved, A. Hauser, S. V. Eliseeva, S. Petoud and C. Piguet, J. Am. Chem. Soc., 2012, 134, 12675.

22 J. Dreiser, K. S. Pedersen, T. Birk, M. Schau-Magnussen, C. Piamonteze, S. Rusponi, T. Weyhermüller, H. Brune, F. Nolting and J. Bendix, J. Phys. Chem. A, 2012, 116, 7842.

23 P.-E. Car, A. Favre, A. Caneschi and R. Sessoli, Dalton Trans., 2015, 44, 15769.

24 S. K. Langley, D. P. Wielechowski, N. F. Chilton, B. Moubaraki and K. S. Murray, Inorg. Chem., 2015, 54, 10497.

25 Agilent Technologies (formerly Oxford Diffraction), Yarnton, Oxfordshire, England, 2012.

26 R. C. Clark and J. S. Reid, Acta Crystallogr., Sect. A: Found. Crystallogr., 1995, 51, 887.

27 CrysAlisPro, Versions 1.171.36.20 (for 1a, 1b, 2)/1.171.38.41 (for 3), Agilent Technologies, Yarnton, Oxfordshire, England, 2012.

28 O. V. Dolomanov, L. J. Bourhis, R. J. Gildea, J. A. K. Howard and H. Puschmann, J. Appl. Crystallogr., 2009, 42, 339.

29 G. M. Sheldrick, Acta Crystallogr., Sect. A: Found. Crystallogr., 2008, 64, 112.

30 G. M. Sheldrick, Acta Crystallogr., Sect. A: Found. Adv., 2015, $71,3$.

31 G. M. Sheldrick, Acta Crystallogr., Sect. C: Struct. Chem., 2015, 71, 3.

32 A. L. Spek, J. Appl. Crystallogr., 2003, 36, 7.

33 C. G. Efthymiou, T. C. Stamataos, C. Papatriantafyllopolou, A. J. Tasiopoulos, W. Wernsdorfer, S. P. Perlepes and G. Christou, Inorg. Chem., 2010, 49, 9737.

34 D. Casanova, M. Llunell, P. Alemany and S. Alvarez, Chem. - Eur. J., 2005, 11, 1479.

35 N. F. Chilton, R. P. Anderson, L. D. Turner, A. Soncini and K. S. Murray, J. Comput. Chem., 2013, 34, 1164.

36 R. L. Carlin, Magnetochemistry, Springer-Verlag, Berlin, Heidelberg, New-York, Tokyo, 1986.

37 K. H. Zangana, E. Moreno Pineda, I. J. Vitorica-Yrezabal, E. J. L. McInnes and R. E. P. Winpenny, Dalton Trans., 2014, 43, 13242.

38 See for examples: (a) A. S. Dinca, A. Ghirri, A. M. Madalan, M. Affronte and M. Andruh, Inorg. Chem., 2012, 51, 3935; (b) T. N. Hooper, J. Schnack, S. Piligkos, M. Evangelisti and E. K. Brechin, Angew. Chem., Int. Ed., 2012, 51, 4633; (c) J.-Z. Qui, L.-F. Wang, Y.-C. Chen, Z.-M. Zhang, Q.-W. Li and M.-L. Tong, Chem. - Eur. J., 2016, 22, 802. 